\title{
PERFORMANCE OF CEMENT COMPOSITES REINFORCED WITH SURFACE-MODIFIED POLYPROPYLENE MICRO- AND MACRO-FIBERS
}

\author{
Jakub Antoš $^{a, *}$, LukÁŠ DejdaR $^{a}$, JAn Trejbal $^{a}$, ZDenĚK ProšeK $^{a, b}$ \\ ${ }^{a}$ Czech Technical University in Prague, Faculty of Civil Engineering, Thákurova 7, 166 29 Prague 6, Czech \\ Republic \\ ${ }^{b}$ Czech Academy of Science, Institute of Physics, Na Slovance 1999/2, 18221 Prague 8, Czech Republic \\ * corresponding author: jakub.antos@fsv.cvut.cz
}

\begin{abstract}
This paper focuses on the mechanical properties investigation of cement pastes reinforced with surface treated polymer fibers. The cement matrix was composed of Portland cement (CEM I 42.5 R, $\mathrm{w} / \mathrm{c}$ ratio equal to 0.4 ). Two polypropylene fiber types (micro- and macro-fibers) were used as randomly distributed and oriented reinforcement in volume amount of $2 \%$. The fibers were modified in the low-pressure inductively coupled cold oxygen plasma in order to enhance their surface interaction with the cement matrix. The investigated composite mechanical properties (load bearing capacity and response during loading) were examined indirectly by means of four-point bending mechanical destructive tests. A response of loaded samples containing treated fibers were compared to samples with reference fibers. Moreover, cracking behavior development was monitored using digital image correlation (DIC). This method enabled to record the micro-cracks system evaluation of both fiber reinforced samples.
\end{abstract}

KEYwORDS: Cement composite, fiber reinforcement, polymeric fiber, surface modification, plasma treatment, four-point bending, DIC, crack pattern.

\section{INTRODUCTION}

Plain concrete can be described as a tension-weak material, where cracks often occur due to exceed of maximal tensile stress, rapid drying, shrinkage, and the like. The crack system development generally increases in the time and thus gradually propagates the concrete volume. As moisture (containing substances and ions), $\mathrm{CO}_{2}$ and other degrading agents comes through formed cracks, service-life, mechanical performance and other properties of the concrete degrade [1].

To reduce all above mentioned phenomena, the utilization of fibers seems to be an effective possibility to control creation, development and width of cracks 2 . During the mixing process, fibers are randomly oriented and distributed throughout the concrete in all directions. Consequently, the fresh concrete is thus protected against excessive formation of plastic shrinkage cracks (concrete tensile strength as well as modulus of elasticity thus increased). In the hardened concrete, the fibers prevent evolution of micro-crack system into macro-crack formation. This is ensured by redistribution of tension stress through the fibers "bridging" a crack (sometimes refereed to as "sewing" effect) and preventing disintegration of broken concrete [1].

In the civil engineering practice, there are several types of fibers used as scattered reinforcements in concrete, e.g. metal, polymer, glass or made of various other materials. The polymer fibers (polypropy- lene or polypropylene-based) are often preferred over steel fibers due to lower production cost, increased resistance to degradation and sufficient mechanical properties (such as tensile strength or toughness) [3]. Moreover, polymeric fibers provide an increase of fire resistance for the structure due to low melting point of the polymers and inferential formation of water vapor capillaries in the structure of concrete [4, 5].

On the other hand, due to low chemical activity of most polymers (related to cement paste), the chemical interaction (bonding) between fiber surfaces and cement matrix is not ensured. The hydrophobic character of fiber surface does not create strong bond with polar liquid (water contained in cement paste). The inter-facial transition zone is thus quite porous, as captured in Fig. 1. Moreover, smooth surfaces of fiber provides insufficient mechanical interaction between the materials. In general, strong inter-phase interaction between matrix and reinforcement is crucial to ensure mechanical (and other) properties of composites [6].

In order to enhance the physico-chemical interaction between the two materials, several types of fiber surface modifications including chemical or physical treatment can be applied [7].

In most cases, the standard treatments have strong impact on fibers mechanical properties. Moreover, the chemical treatment is not environmentally friendly and is too time and energy consuming (an exposition fiber to alkali solution lasts up to tens of hours and whole process requires high temperature) [ 8 . 


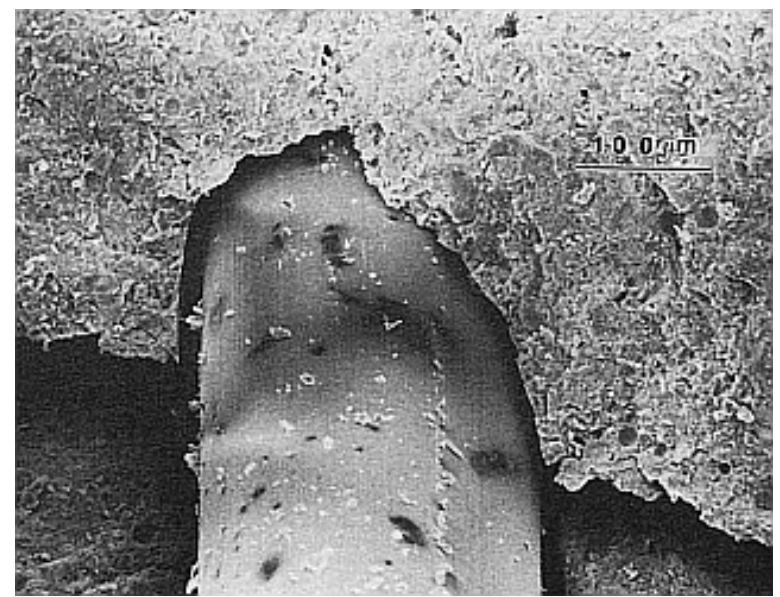

Figure 1. Porous inter-facial transition zone between mono-filament fiber and cement matrix [7].

The plasma treatment seems to be an effective and thrifty method to modify both physical and chemical polymer surface. The physical treatment rests in a roughening via ion bombardment. Unlike the conventional physical methods, this influences only the monomolecular layer, so fiber mechanical performance remains almost untouched. Next to that, the chemical modifications rest in an activation of surfaces due to interaction between polymeric chains and free radicals. The active polar groups are implemented onto fiber surfaces and thus change hydrophobic characteristic to hydrophilic [9, 10]. The most suitable time to modify polymeric micro-fiber using plasma treatment is 30 seconds according to [11, 12.

In presented study, we focused on inter-face interaction between reference and plasma treated fibers with cement matrix. We modified two fiber types polypropylene micro- and macro-fibers, as the common representatives of reinforcement in the field of concrete constructions. We modified the fibers by low-pressure cool oxygen plasma treatment. As an indirect indicator of interaction between the two materials, we have done four-point bending tests of fiber reinforced prismatic cement specimens when we focused on their mechanical response. Moreover, we recorded the specimens behavior during loading using digital image correlation.

\section{MATERIALS}

\subsection{POLYMERIC FIBERS}

Two types of polypropylene (PP) fibers differing in dimensions were used. Micro-fibers having $18 \mu \mathrm{m}$ in diameter and approx. $12 \mathrm{~mm}$ of length (commercial name: Stavon, manufacturer: Trevos, s. r. o., Czech Republic) were used for reinforcement of the first set of cement composite samples. These fibers were surface treated by a fabric softener. According to product data sheet, material properties of the fibers are declared as: UTS $\approx 273 \mathrm{MPa}$ (ultimate tensile strength calculated from dTex unit) and ductility $=$
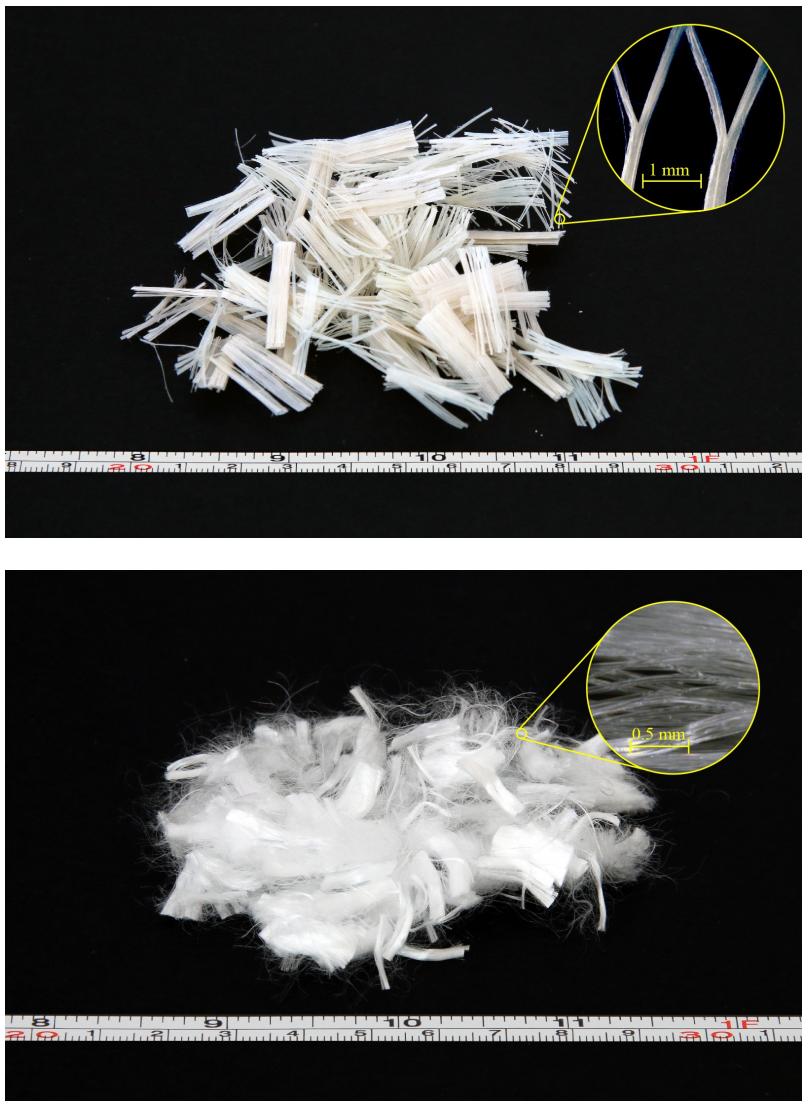

Figure 2. Top - Polypropylene macro-fibers, Bottom - Polypropylene micro-fibers.

min. $50 \%$. No other information about the fibers is provided by the manufacturer.

For the second set of experiment samples, the dimensions of used fibers were $80 \mu \mathrm{m}$ in diameter and $\approx 19 \mathrm{~mm}$ of length (commercial name: HighGrade, manufacturer: Brugg Contec AG, Switzerland). The basic material properties listed in data sheet of the product are as follows: $\varrho=910 \mathrm{~kg} \mathrm{~m}^{-3}$ (volumetric mass density), UTS $=400 \mathrm{MPa}, \mathrm{E}=4.9 \mathrm{GPa}$ (Young's modulus of elasticity), $\mathrm{mp} \approx 150{ }^{\circ} \mathrm{C}$ (melting point). According to European standard code [5], cementitious composite reinforced by above described macro-fibers is classified as construction concrete, not plain. Both types of fibers are captured in Figure 2.

\subsection{Cement PASte}

Prismatic specimens composed of cement paste (CEM I $42.5 \mathrm{R}$, water to cement ratio 0.4 ) and polymer fiber reinforcement were made using metal forms of $40 \times 40 \times 160 \mathrm{~mm}$ dimensions. On the whole, four different mixtures were prepared (reference and treated, micro- and macro-fibers). The amount of fiber reinforcement was equal to $2 \%$ of sample volume. After 1 day, the prepared samples were cast out from forms and stored in a water environment to prevent degradation for other 27 days (total age of samples equal to standard 28 days), when the samples were tested. 


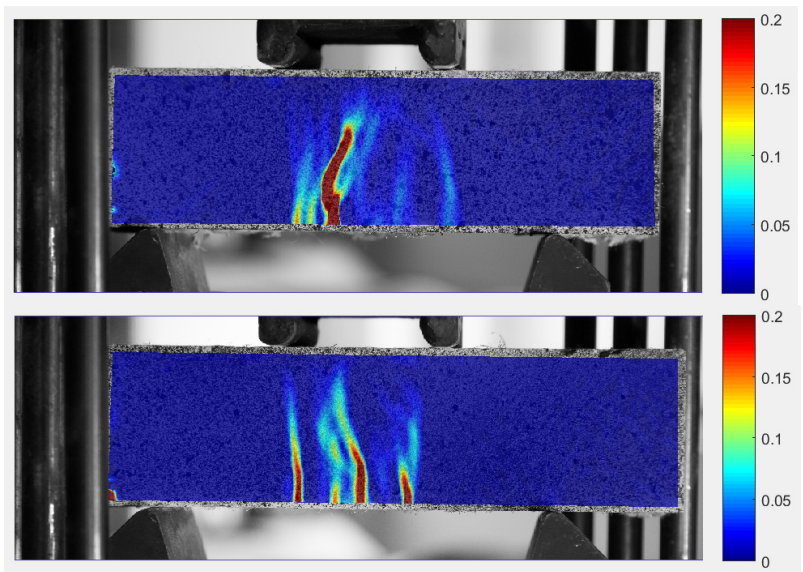

FiguRE 3. Crack development during four-point bending test of cement sample reinforced with reference (top) and 30 seconds plasma treated (bottom) microfibers.

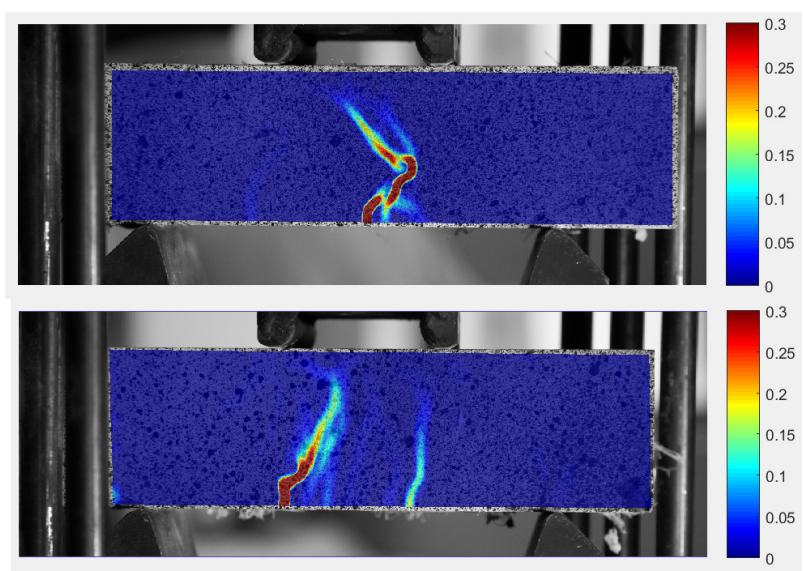

Figure 4. Crack development during four-point bending test of cement sample reinforced with reference (top) and 30 seconds plasma treated (bottom) macrofibers.

\section{EXPERIMENTAL METHODS}

\subsection{Plasma treatment}

Both macro- and micro-fibers were modified in order to change their surface properties by means of plasma treatment. Concretely, low-pressure cool oxygen coupled plasma treatment was done using Tesla VT 214 (13.56 MHz) device. The plasma treatment duration was equal to $30 \mathrm{~s}$. Other treatment parameters were as follows: $100 \mathrm{~W}$ total power of RF source, $20 \mathrm{~Pa}$ total gas pressure, $50 \mathrm{sccm} \mathrm{O}_{2}$ flow. After plasma treatment, the fibers were admixed into fresh cement paste immediately.

\subsection{FOUR-POINT BENDING TEST}

The interface interaction between fibers and cement matrix was assessed by the destructive four-point bending tests. The indirect testing was executed as reimbursement of standard single-fiber pull-out test due to complicated fiber dimensions and shapes. Each type of mixture was represented by 6 specimens in order to obtain statistically relevant set of results.

The prismatic cementitious composite specimens were tested on loading frame Web Tiv Ravestein FP 100. Base-span was equal to $120 \mathrm{~mm}$. The test was displacement controlled with $1 \mathrm{~mm} / \mathrm{min}$ rate of loading and it was interrupted when the mid-span displacement reached $4 \mathrm{~mm}$ and $3 \mathrm{~mm}$ in the case of samples reinforced with micro- and macro-fibers, respectively. The main focus of the experiment was on the post cracking phase with expected increase of sample toughness.

\subsection{Digital image correlation}

The behavior of cracks was observed using digital image analysis (DIC). DIC analysis allowed to image the amount, shape and position of cracks graphically and thus answer the question how the specimens resisted to loading in the post-cracking phase (single vs. multiple cracking behavior) [14]. As the result of the analysis, cracking patterns were visualized with a map of maximum principal strain in which concentrations can be attributed the crack formation.

To allow the DIC observation, the samples were equipped with artificial stochastic contrast pattern onto their surfaces. Images used for DIC analysis were taken with DSLR camera Canon EOS 70D fitted with Canon zoom lens EF-S 17-85 IS USM. The exposition parameters were as follows, shooting interval $10 \mathrm{sec}-$ onds, ISO speed 100, focal length $50 \mathrm{~mm}$, aperture value 4.5 , shutter speed $1 / 100 \mathrm{sec}$.

\section{Results}

\subsection{SAMPLES REINFORCED WITH MICRO-FIBERS}

It was shown, that maximum load-bearing capacity of cement samples reinforced with micro-fibers $(\mathrm{d}=18 \mu \mathrm{m})$ was lower than $7 \mathrm{kN}$ when reference fibers were used and almost $8 \mathrm{kN}$ in the case of plasma modified fibers. The residual toughness of specimens containing surface treated fibers in the post cracking phase (namely after $3 \mathrm{~mm}$ mid-span displacement) was significantly higher, if compared to the referential specimens. This phenomenon can be attributed to increase of adhesion between pulling-out fibers from matrix when sample underwent deformation. Nevertheless, slight increase of initial toughness in the linear-elastic phase of loaded samples was also recorded. It was probably caused by reduction of amount and wight of shrinkage cracks. The force-displacement diagram is shown in Fig. 5.

DIC analysis showed that loaded cement sample was damaged by one single crack, which was opened when the displacement was increased in the case of reference fibers. On the other hand, sample reinforced with surface treated fibers was damaged by systems of cracks, known as multiple cracking behavior. The principal strain diagrams are shown in the Fig. 3. 


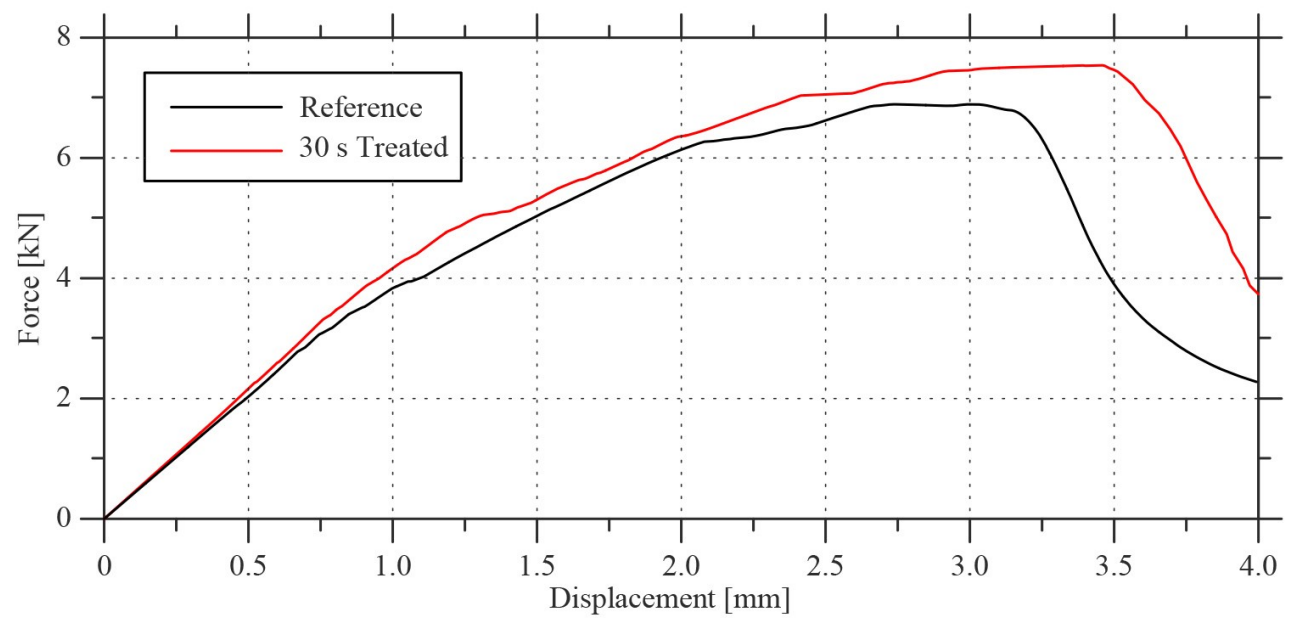

Figure 5. Force-displacement diagram of cement samples containing micro-fibers.

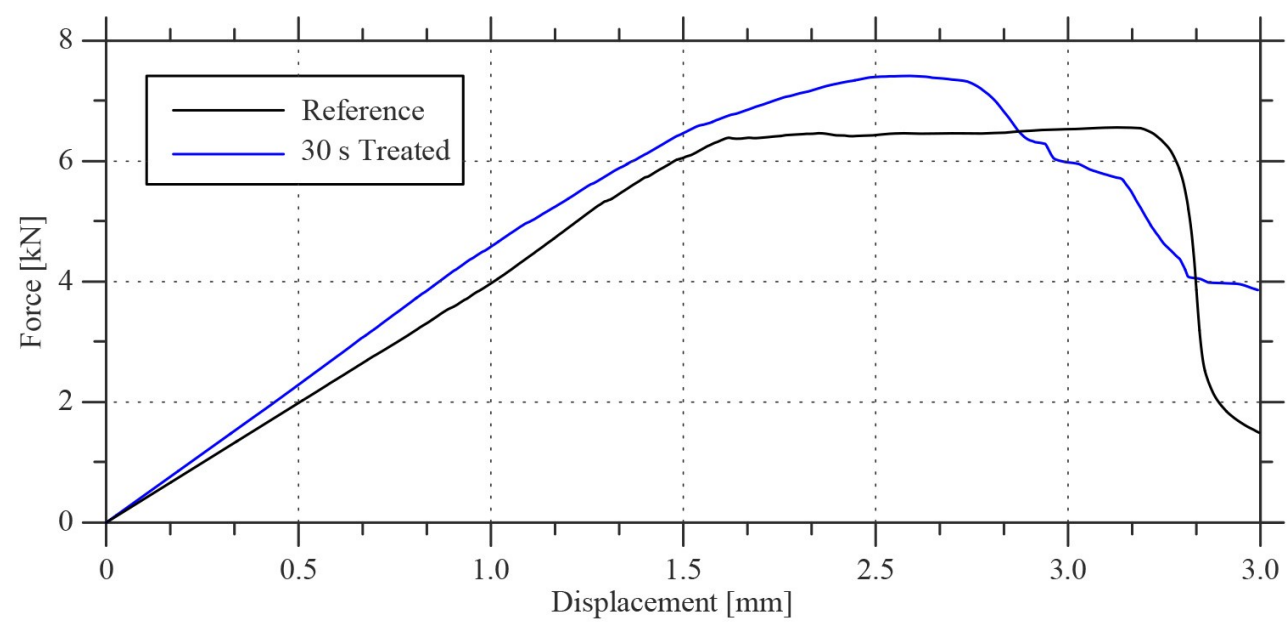

FIgURE 6. Force-displacement diagram of cement samples containing micro-fibers.

\subsection{Samples REINFORCED With MACRO-FIBERS}

Loading response of cement samples reinforced with macro-fibers $(\mathrm{d}=80 \mu \mathrm{m})$ exhibited similar results compared to micro-fiber reinforcement. The maximum reached force of reference specimens can be found close to $6 \mathrm{kN}$. The plasma treated fiber-reinforced samples reached load-bearing capacity close to $8 \mathrm{kN}$. However, the residual toughness of samples beyond mid-span deflection of $3 \mathrm{~mm}$ did not meet the expectations, compared to the reference specimens. This phenomenon seemed to be accidental. The recording of the test (Fig. 6) also captured slight increment modified composite elastic modulus.

Similarly to micro-fibers, the behavior monitored using DIC technique during four-point bending tests can be described as single crack and multi cracking in the case of samples reinforced with reference and plasma treated fibers, respectively. The results of DIC analysis are shown in the Fig. 4

\subsection{CONCLUSION}

The main goal of this work was to enhance inter-phase interaction between cement matrix and polymer fiber reinforcement. The matrix was composed of Portland cement (CEM I $42.5 \mathrm{R}$, w/c ratio equal to 0.4 ). As the randomly dispersed and oriented reinforcement, two types of polypropylene fibers having $18 \mu \mathrm{m}$ and $80 \mu \mathrm{m}$ in diameter were used.

The interaction between the two materials was enhanced via fiber surfaces modification by low-pressure cool coupled oxygen plasma. A duration of fiber exposition to plasma was equal to 30 seconds.

Prismatic specimens having dimensions equal to $40 \times 40 \times 160 \mathrm{~mm}$ contained from the matrix and fibers (volume amount $2 \%$ ) were made and after 28 days of mixture curring and hardening subjected to four-point bending destructive tests. As an indirect indicator of both chemical and physical interaction between the two materials, the response (toughness and loadbearing capacity) of loaded specimens was monitored and evaluated. The results of samples reinforced with reference and treated fibers were mutually compared.

The increase of load-bearing capacity of samples re- 
inforced with modified fibers (both micro- and macrofibers) was shown. Compare to reference mixtures, specimens containing modified fibers exhibited toughness increase in both linear and post-cracking phase. Also, as for the plasma treated micro-fiber reinforced samples, significant increase of residual toughness (compared to reference specimens) was observed. Similar findings were pointed out in the study examining the interaction between plasma modified PET (polyethylene terephthalate) and cement matrix [13].

DIC analysis revealed a different behavior during four-point bending tests between samples containing reference and modified fibers. While the behavior can be described as single crack in the case of reference mixtures, the mixtures with modified fibers exhibited multi cracking behavior. This phenomenon clearly point to the required increase of the adhesion between treated fibers and the cement matrix.

Based on these findings, it can be pointed out, that polymer fiber modification via plasma treatment can be assumed as low-cost and very effective method to increase inter-phase interaction and mechanical properties of fiber reinforced cement composites.

\section{ACKNOWLEDGEMENTS}

This work was financially supported by Czech Technical University in Prague - SGS project SGS16/201/OHK1/3T/11 and by the Czech Science Foundation research project $15-12420$ S. The authors would also like to thank to Tereza Horová for her help with this research.

\section{REFERENCES}

[1] P.S. Song, S. Hwang, B.C. Sheu, Townsend T.G., Strength properties of nylon and polypropylene fiber-reinforced concretes. Cement and Concrete Research 35(8):1546-1550, 2005.

DOI: $10.1016 /$ j.cemconres.2004.06.033

[2] N. Banthia, R. Gupta, Influence of polypropylene fiber geometry on plastic shrinkage cracking in concrete, Cement and Concrete Research 36(7): 1263-1267, 2006. DOI: 10.1016/j.cemconres.2006.01.010

[3] S. Kakooei, H. Akil, M. Jamshidi, J. Rouhi, The effects of polypropylene fibers on the properties of reinforced concrete structures, Construction and Building Material 27(1): 73-77, 2012. DOI:

10.1016/j.conbuildmat.2011.08.015
[4] EN 14889-2, Fibers for concrete- Part 2: Polymer fibers - Definitions, specifications and conformity.

[5] M. Zeiml, D. Leithner, R. Lackner, H.A. Mang, How do polypropylene fibers improve the spalling behavior of in-situ concrete?, Cement and Concrete Research 36(5): 929-942, 2006. DOI: 10.1016/j.cemconres.2005.12.018

[6] J. Topič, J. Bartoš, L. Kopecký, J. Fládr, Z. Prošek, J. Trejbal, Development of mechanical properties of a cement composite reinforced with synthetic fibers, Trans Tech Publications LTD, 332-335, 2016.

[7] A. Peled, H. Guttman, Treatments of polypropylene fibres to optimize their reinforcing efficiency in cement composites, Cement and Concrete Composites 14(4): 277-285, 1992. DOI: 10.1016/0958-9465(92)90026-R

[8] V. Machovič, L. Lapčák, L. Borecká, M. Lhotka, J. Andertová, L. Kopecký, L. Mišková, Microstructure of interfacial tranyition yone between PET fibres and cement paste, Acta Geodyn. Geomater. 10(169): 121-127, 2013. DOI: 10.13168/AGG.2013.0012

[9] A.M. López-Buendía, M.D. Romero-Sánchez, V. Climent, C. Guillem, Surface treated polypropylene (PP) fibers for reinforced concrete, Cement and Concrete Research 54: 29-35, 2013. DOI: 10.1016/j.cemconres.2013.08.004

[10] J. Trejbal, V. Šmilauer, A. Kromka, Š. Potocký, L. Kopecký, Wettability enhancement of polymeric and glass micro fiber reinforcement by plasma treatment, in: Proceedings Nanocon, Brno, 2015.

[11] J. Trejbal, J. Fládr, L. Kopecký, Utilization of plasma treated polymeric macro-fibers as reinforcement in concrete constructions, Advanced Materials Research 1144: 70-75, 2016. DOI: 10.4028/www.scientific.net/AMR.1144.70

[12] B.H. Yang et al., Strength characteristics of modified polypropylene fiber and cement-reinforced loess, Journal of Central South University 24(3): 560-568, 2017.

[13] J. Trejbal et al., Impact of surface plasma treatment on the performance of PET fiber reinforcement in cementitious composites, Cement and Concrete Research 89: 276-287, 2016. DOI: 10.1016/j.cemconres.2016.08.01

[14] B. Pan et al., Full-field strain measurement using a two- dimensional Savitzky-Golay digital differentiator in digital image correlation, Optical Engineering 46: 1-10, 2007. DOI: 10.1016/j.cemconres.2016.08.01 